\title{
Effect of Severe Plastic Deformation on Structure Refinement and Mechanical Properties of the Al-Zn-Mg-Fe-Ni Alloy
}

\author{
Irina Brodova ${ }^{1}\left(\mathbb{D}\right.$, Dmitriy Rasposienko ${ }^{1}$, Irina Shirinkina ${ }^{1}$, Anastasia Petrova ${ }^{1, *}$, Torgom Akopyan ${ }^{2}$ and \\ Elena Bobruk ${ }^{3,4}$
}

check for updates

Citation: Brodova, I.; Rasposienko,

D.; Shirinkina, I.; Petrova, A.;

Akopyan, T.; Bobruk, E. Effect of Severe Plastic Deformation on Structure Refinement and Mechanical Properties of the Al-Zn-Mg-Fe-Ni Alloy. Metals 2021, 11, 296. https:// doi.org/10.3390/met11020296

Academic Editor: Christine Borchers Received: 28 December 2020

Accepted: 31 January 2021

Published: 9 February 2021

Publisher's Note: MDPI stays neutral with regard to jurisdictional claims in published maps and institutional affiliations.

Copyright: (c) 2021 by the authors. Licensee MDPI, Basel, Switzerland. This article is an open access article distributed under the terms and conditions of the Creative Commons Attribution (CC BY) license (https:// creativecommons.org/licenses/by/ $4.0 /)$.
1 Mikheev Institute of Metal Physics, Ural Branch, Russian Academy of Sciences, 620108 Ekaterinburg, Russia; ibrodova@mail.ru (I.B.); dmitrijrasp@gmail.com (D.R.); shirinkina@imp.uran.ru (I.S.)

2 Metal Forming Department, National University of Science and Technology MISiS, 119991 Moscow, Russia; aktorgom@gmail.com

3 Institute of Physics of Advanced Materials, Ufa State Aviation Technical University, 450008 Ufa, Russia; e-bobruk@yandex.ru

4 Laboratory for Mechanics of Bulk Nanostructured Materials, Saint Petersburg State University, 198504 Saint Petersburg, Russia

* Correspondence: petrovanastya@yahoo.com; Tel.: +7-950-647-3501

\begin{abstract}
This paper identifies the mechanisms of phase and structural transformations during severe plastic deformation by shearing under pressure (high-pressure torsion) of an $\mathrm{Al}-\mathrm{Zn}-\mathrm{Mg}$ Fe-Ni-based aluminum alloy depending on different initial states of the material (an ingot after homogenizing annealing and a rod produced by radial-shear rolling). Scanning and transmission electron microscopy are used to determine the morphological and size characteristics of the structural constituents of the alloy after high-pressure torsion. It has been found that, irrespective of the history under high-pressure torsion, fragmentation and dynamic recrystallization results in a nanostructural alloy with a high microhardness of 2000 to $2600 \mathrm{MPa}$. Combined deformation processing (highpressure torsion + radial-shear rolling) is shown to yield a nanocomposite reinforced with dispersed intermetallic phases of different origins, namely $\mathrm{Al}_{9} \mathrm{FeNi}$ eutectic aluminides and $\mathrm{MgZn} \mathrm{n}_{2}, \mathrm{Al}_{2} \mathrm{Mg}_{3} \mathrm{Zn}_{3}$, and $\mathrm{Al}_{3} \mathrm{Zr}$ secondary phases. The results of uniaxial tensile testing demonstrate good mechanical properties of the composite (ultimate tensile strength of $640 \mathrm{MPa}$, tensile yield strength of $628 \mathrm{MPa}$, and elongation of $5 \%$ ).
\end{abstract}

Keywords: Al-Zn-Mg alloy; nanomaterials; nanocomposite; high pressure torsion; fragmentation; dynamic recrystallization; hardening; $\mathrm{MgZn}_{2} ; \mathrm{Al}_{2} \mathrm{Mg}_{3} \mathrm{Zn}_{3} ; \mathrm{Al}_{3} \mathrm{Zr}$; tensile test; transmission electron microscopy

\section{Introduction}

At present, Al-based composite materials are known to become increasingly important, for they have essential advantages over conventional commercial alloys due to a favorable combination of practical design characteristics and functional properties [1-4]. For example, aluminum-matrix composite materials reinforced with silicon carbide are used in automobile industry, aerospace engineering and other industries owing to high wear resistance, high specific strength, and heat conductivity [5-7]. It was shown that silicon carbide reinforced aluminum matrix composites are effectively additionally alloyed with the chromium [8]. The authors have found that the aluminum matrix composites with a varying weight percent of chromium (0-3 wt\%) and a fixed percentage of silicon carbide $(10 \%)$ were formed through the vortex casting. It was found that the chromium additive in the Al-SiC composites significantly improved the hardness, friction coefficient, and mechanical properties (strength, abrasion resistance, and wear resistance). Borides, nitrides, and oxides of refractory metals are often used as reinforcement particles for the Al matrix; the disperse phases of these particles reinforce the plastic Al matrix, thus creating 
barriers for the migration of dislocations and grain boundaries [1-3]. Besides artificial composites, which are produced by mechanical alloying or by powder metallurgy, there is a big class of natural aluminum-based eutectic composite materials. Typical examples of such alloys are represented by Al-Si alloys (silumins). New advanced alloys based on Al-Fe, $\mathrm{Al}-\mathrm{Ni}$, and $\mathrm{Al}-\mathrm{Fe}-\mathrm{Ni}$ eutectics have lately been developed and termed nickalins [9-11]. Well-known compositions of the 7xxx series-i.e., alloys belonging to the $\mathrm{Al}-\mathrm{Zn}-\mathrm{Mg}-\mathrm{Cu}$ system-were proposed as the $\mathrm{Al}$ matrix of these alloys. Economical $\mathrm{Al}-\mathrm{Zn}-\mathrm{Mg}$ alloys with a total $\mathrm{Fe}$ and $\mathrm{Ni}$ content of $1 \mathrm{wt} \%$ are highly technological due to the eutectic constituent $\left(\mathrm{Al}+\mathrm{Al}_{9} \mathrm{FeNi}\right)$ and have high strength characteristics resulting from a dispersion-hardened Al matrix [10,11].

The state-of-the-art trend in improving the structure and properties of commercial alloys is the application of methods of severe plastic deformation, the best-studied ones being equal-channel angular pressing (ECAP) [12-14], equal channel angular extrusion (ECAE) [15-18], and torsion in Bridgman anvils (HPT) [19-21]. New SPD methods have been developed in recent years. For example, there are an accumulative roll bonding (ARB) $[22,23]$ and a differential velocity sideways extrusion (DVSE) $[24,25]$. DVSE is a novel method for directly forming curved profiles from billets in one extrusion operation using two opposing punches. Modeling the process, authors [24] identified that a curvature of extrudate can be controlled and varied using a difference between the velocities of the two punches, defined by velocity ratio, as well as an extrusion ratio. The effectiveness of the new SPD method was tested during manufacturing a curved AA1050 bar widely used in the transport industry [25]. Due to the severe strains arising in the DVSE process, (greater than that for conventional pass of equal channel angular extrusion), significant grain refinement in the curved bar (grain size $\sim 3 \mu \mathrm{m}$ ) from the original billet (grain size $\sim 357 \mu \mathrm{m}$ ) was achieved in one extrusion operation. On the basis of structural studies, the authors found that grain refinement in the DVSE process is due mainly to continuous dynamic recrystallization. The refinement of the structure led to an increase in mechanical properties. Compared with the billet, the hardness, yield strength, and ultimate tensile strength of the formed curved bar increase by $134.8 \%, 354.0 \%$, and $116.8 \%$ respectively, although the elongation to fracture was decreased by $60.0 \%$. DVSE method includes hot extrusion (DVSE-HE), welding extrusion (DVSE-WE), and coextrusion (DVSE-CE). DVSE-CE technology used for a forming curved $\mathrm{Al} / \mathrm{Mg}$ sandwich bar was described in [26].

According to $[14,17,18,27-29]$ submicrocrystalline and nanocrystalline alloys of 7XXX series exhibit a good combination of strength and plastic properties resulting from thermal deformation processing under different conditions.

The analysis of the available results on the design of high-strength Al-Zn-Mg-alloybased composites raises a question of how the shape, size, and amount of $\mathrm{Al}_{9} \mathrm{FeNi}$ eutectic aluminides change and how this affects the structure, phase composition, and properties of nickalins as a whole. The first studies along this line have been conducted in the last three years [30-32]. The effect of thermal pretreatment on the deformation behavior of nickalin under high-pressure torsion (HPT) was established [30], the sequence and kinetics of postdeformation processes under heating to $400{ }^{\circ} \mathrm{C}$ were determined [31], and the dynamic properties of an Al-Zn-Mg-Fe-Ni alloy before and after HPT in a wide range of strain rates, $10^{3}$ to $10^{5} \mathrm{~s}^{-1}$, were measured [32]. The results have shown that the principal mechanisms of structure formation in a 7xxx series alloy under HPT remain the same, but the presence of $\mathrm{Al}_{9} \mathrm{FeNi}$ eutectic aluminides in the composite structure affects the morphology and kinetics of the precipitation of secondary phases and increases the thermal stability of the composite and its strength.

It was reported in [33] that radial-shear rolling is an effective method for increasing the mechanical properties of nickalin through creating a microscale gradient structure and a uniform distribution of strengthening phases in it.

The purpose of this paper is to continue the study aimed at creating a composite material based on an Al-Zn-Mg-Fe-Ni alloy by combining thermal and deformation pro- 
cessing techniques. Particularly, the effect of complex deformation processing including RSR and HPT on the structural and phase transformations of the Al-Zn-Mg-Fe-Ni alloy and its mechanical properties is discussed. In view of the complex chemical composition of the alloy, it is obvious that the intermetallic phases of different origins make a great contribution to the formation of its structure and properties; therefore, the paper focuses on studying the evolution of their formation mechanisms under HPT with the application of high-resolution TEM methods.

\section{Materials and Methods}

A high-strength Al-Zn-Mg-Fe-Ni alloy (nickalin) was studied. The chemical composition of the experimental alloy is given in Table 1.

Table 1. Chemical composition ( $w \mathrm{t} \%$ ) of the experimental alloy.

\begin{tabular}{ccccccc}
\hline Al & Zn & Mg & Fe & Ni & Zr & Cu \\
\hline Base & 7.22 & 2.95 & 0.52 & 0.57 & 0.2 & 0.002 \\
\hline
\end{tabular}

The ingot production conditions, and the raw material composition are described in detail in $[11,33]$. The melting was carried out in an electric resistance furnace in graphite -chased crucible based on high purity $\mathrm{Al}(99.99 \%)$. $\mathrm{Zn}$ and $\mathrm{Mg}$ were introduced into $\mathrm{Al}$ melt in the form of pure metals, whereas $\mathrm{Fe}, \mathrm{Ni}$ and $\mathrm{Zr}$ in the form of binary master alloys (Al-10\% Fe, Al-20\% Ni, Al-1.5\% Zr). The casting was carried out in a metal mold at a temperature of $780^{\circ} \mathrm{C}$ (cooling rate during solidification was $\sim 10 \mathrm{~K} / \mathrm{s}$ ). The ingots were subjected to two-stage homogenizing annealing at $450{ }^{\circ} \mathrm{C}$ and $540{ }^{\circ} \mathrm{C}$ with holding for three hours in each stage. The alloy was studied in the form of ingots, calibrated rods and disks produced by HPT at room temperature.

The ingots were turned to a diameter of $40 \mathrm{~mm}$, heated in an oven to $480{ }^{\circ} \mathrm{C}$, and subjected to two-pass radial shear rolling (RSR) in MiSiS $100 \mathrm{~T}$ and 14-40 mills [33]. The total rod elongation ratio was 2.78 , the diameter of the initial billet was $31 \mathrm{~mm}$, and the diameter of the resulting rod was $24 \mathrm{~mm}$.

Severe plastic deformation by HPT was performed on 20-mm-diameter and 1-mmthick specimens cut from an ingot (nickalin 1) and a rod after RSR (nickalin 2). The number of anvil revolutions was $n=5,10,15$, for the true accumulated strains (with allowance for upsetting) $\varepsilon=6.0,6.7$, and 7.1, respectively. The mechanical properties were determined on flat microspecimens (5.7 $\mathrm{mm}$ long, $2 \mathrm{~mm}$ wide, and $1 \mathrm{~mm}$ thick) in a Shimadzu AGX-50 Plus (Kyoto, Japan) universal testing machine. To fix the microspecimens in the grips of the testing machine, we used a special clamping device described in detail in [34]. The strain rate was $5 \times 10^{-4} \mathrm{~s}^{-1}$.

The mechanical properties were estimated from the values of tensile yield strength YS, ultimate tensile strength UTS, and percentage elongation $\delta$. Microhardness $\mathrm{H}_{\mathrm{v}}$ was determined at a load of $0.2 \mathrm{~N}$ in a PMT-3 device (Moscow, Russia). The measurement error was at most $10 \%$. Hardness was measured by the Brinell method, with a $5 \mathrm{~mm}$ ball, at a load of $250 \mathrm{~kg}$. The specimen structure was studied at different scale levels by means of a Neophot-32 optical microscope (OM, Carl Zeiss, Jena, Germany), a Quanta 200 scanning electron microscope (SEM, FEI Company, Hillsboro, OR, USA), and a Tecnai G $^{2} 30$ Twin transmission electron microscope (TEM, FEI Company, Oregon, USA) with an accelerating voltage of $300 \mathrm{kV}$. X-ray diffraction (XRD) analysis was carried out using an Empyrean diffractometer (PANanalytical, Almelo, The Netherlands) at room temperature and $\mathrm{Cu} \mathrm{K} \alpha$ radiation. Based on the X-ray diffraction data the lattice parameter of an Al-matrix was calculated. The specimens for ${ }^{a}$ analysis were made with the use of mechanical polishing on a diamond suspension. Final smoothing was performed on a suspension of colloidal silicon dioxide. The specimens for thin structure examination were made by jet polishing in a Tenupol-5 (Struers, Denmark) in a $20 \%$ nitric acid solution and $80 \%$ methanol at a temperature of $-25{ }^{\circ} \mathrm{C}$ and a voltage of 15 to $20 \mathrm{~V}$. The size of the structural constituents 
was quantitatively analyzed from dark-field images with the use of the SIAMS 700 image analysis program (Russia).

\section{Results}

\subsection{Structure and Phase Composition of the Alloy before HPT}

$\mathrm{Al}-\mathrm{Zn}-\mathrm{Mg}-\mathrm{Fe}-\mathrm{Ni}$ alloy specimens of the same composition but different histories were the initial materials for severe plastic deformation (SPD). Batch I specimens (nickalin 1) were cut from the ingot and annealed in two stages at 450 and $540{ }^{\circ} \mathrm{C}$ with a $3 \mathrm{~h}$ holding at each stage. Their structure and properties were described in detail in [32]. Heat treatment forms a structure consisting of an $\mathrm{Al}$ matrix and $\mathrm{Al}_{9} \mathrm{FeNi}$ eutectic aluminides located on the grain boundaries and dendritic cells. The grain size of the Al matrix is $380 \mu \mathrm{m}$ and that of the eutectic aluminides is 2 to $3.5 \mu \mathrm{m}$. Besides, inside the grains of the $\mathrm{Al}$ solid solution there are precipitates of the secondary T-phase $\left(\mathrm{Al}_{2} \mathrm{Zn}_{3} \mathrm{Mg}_{3}\right)$ resulting from ingot cooling after homogenization.

A 24-mm-diameter rod produced by RSR at $480{ }^{\circ} \mathrm{C}$ after two passes was an object for HPT of batch II specimens (nickalin 2). Figure 1 shows the rod cross-section structure.

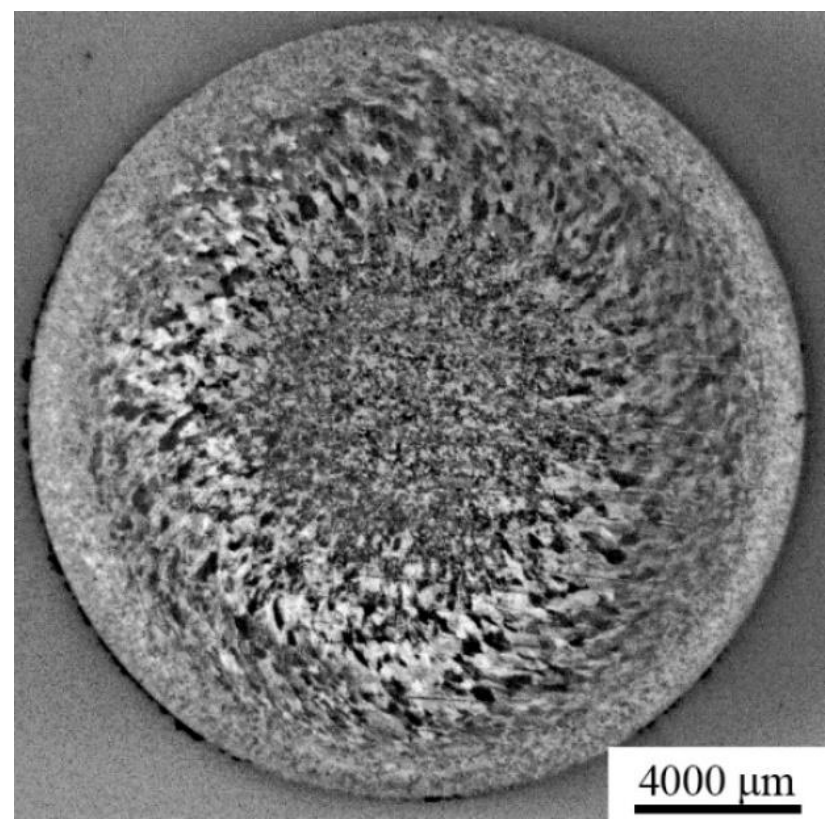

Figure 1. Microstructure in cross-section of the nickalin 2 rod after RSR (OM).

Three zones with a gradient structure typical for this RSR pattern are clearly visible. The width of the SPD zone on the rod periphery is $\sim 2.5$ to $3.0 \mathrm{~mm}$; the middle zone at half the radius and the central zone have a width of 4.0 to $4.5 \mathrm{~mm}$ each. The gradient structure is characterized by different hardness values. The mid-radius zone has a hardness of $105 \mathrm{HB}(105 \mathrm{HV})$, whereas the hardness in the central zone decreases to $97 \mathrm{HB}(97 \mathrm{HV})$. In the peripheral zone, there is a dynamically recrystallized structure with the grain size increasing from $3 \mathrm{~mm}$ at the surface to $8 \mathrm{~mm}$ at the boundary with the second zone formed by the hot-deformed structure (Figure 2a). In the peripheral zone, the intermetallic particles become fragmented due to deformation and arrange themselves along the direction of rolling (Figure $2 b$ ). Elements of the cast structure of the matrix and eutectic conglomerates are preserved in the central part, the shape and size of aluminides being changed only slightly from the as-cast condition (Figure 2c,d). The EDS element analysis of these crystals has shown that they contain $\mathrm{Fe}$ and $\mathrm{Ni}$, i.e., they belong to the $\mathrm{Al}_{9} \mathrm{FeNi}$ phase (Figure 2e). 


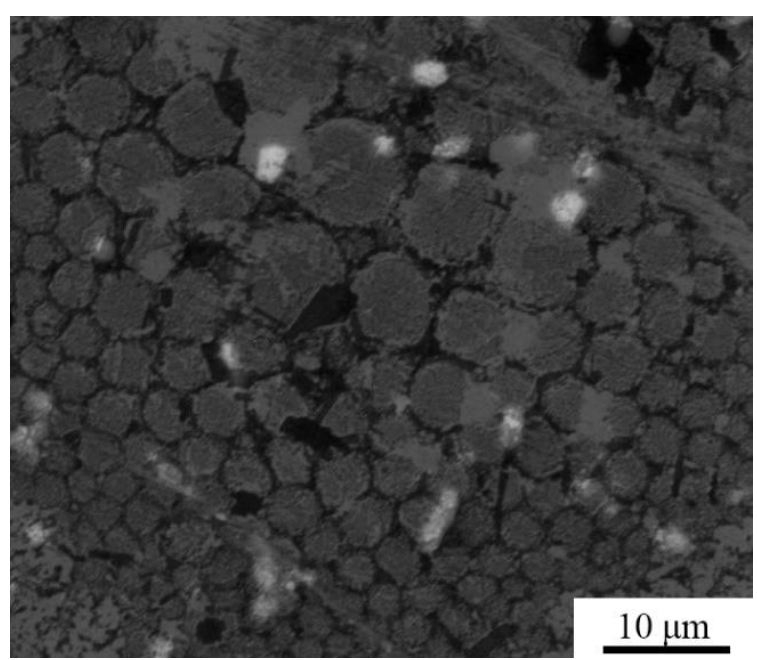

(a)

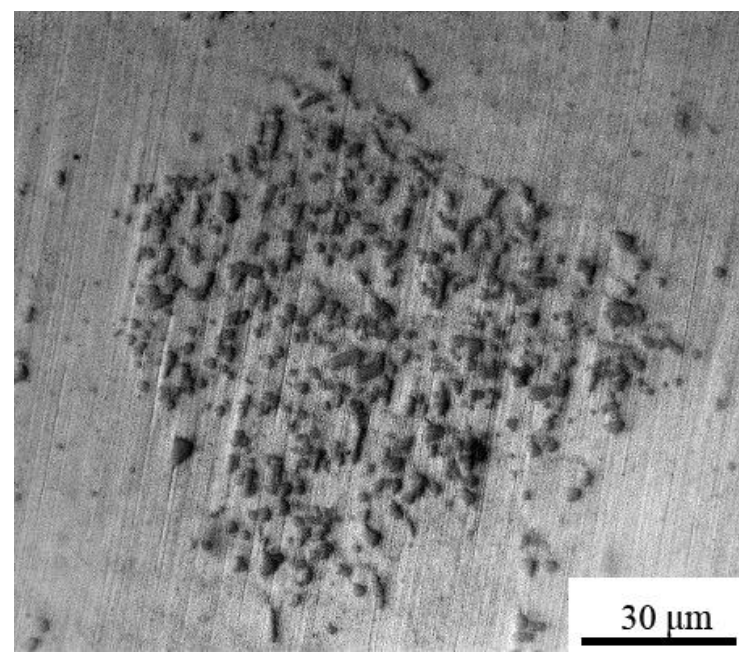

(c)

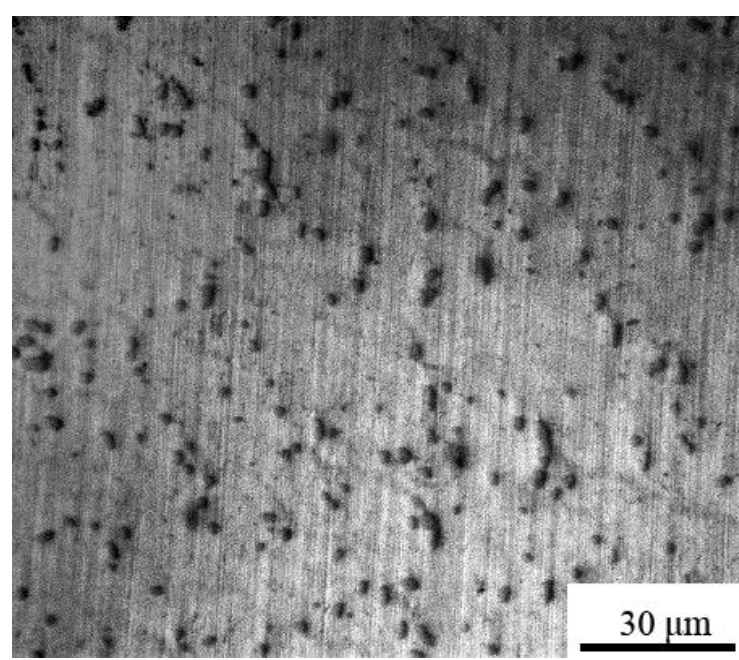

(b)

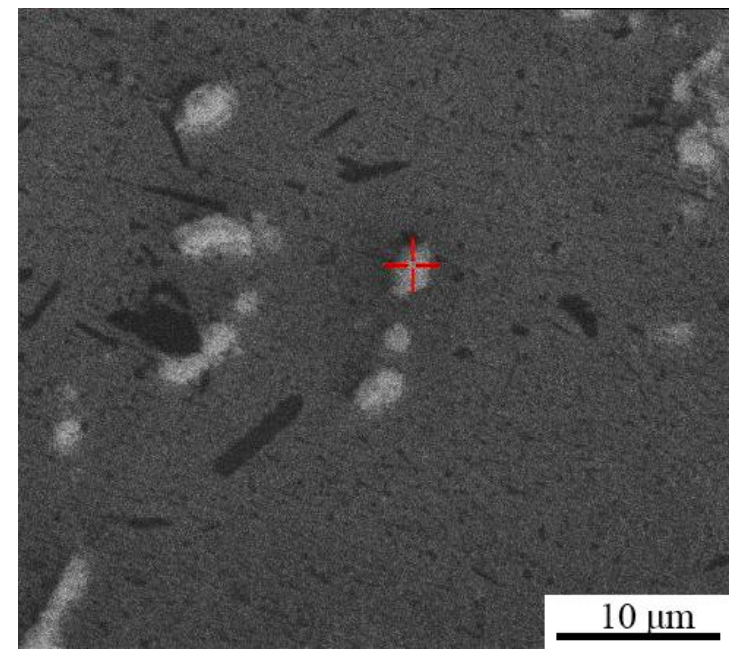

(d)

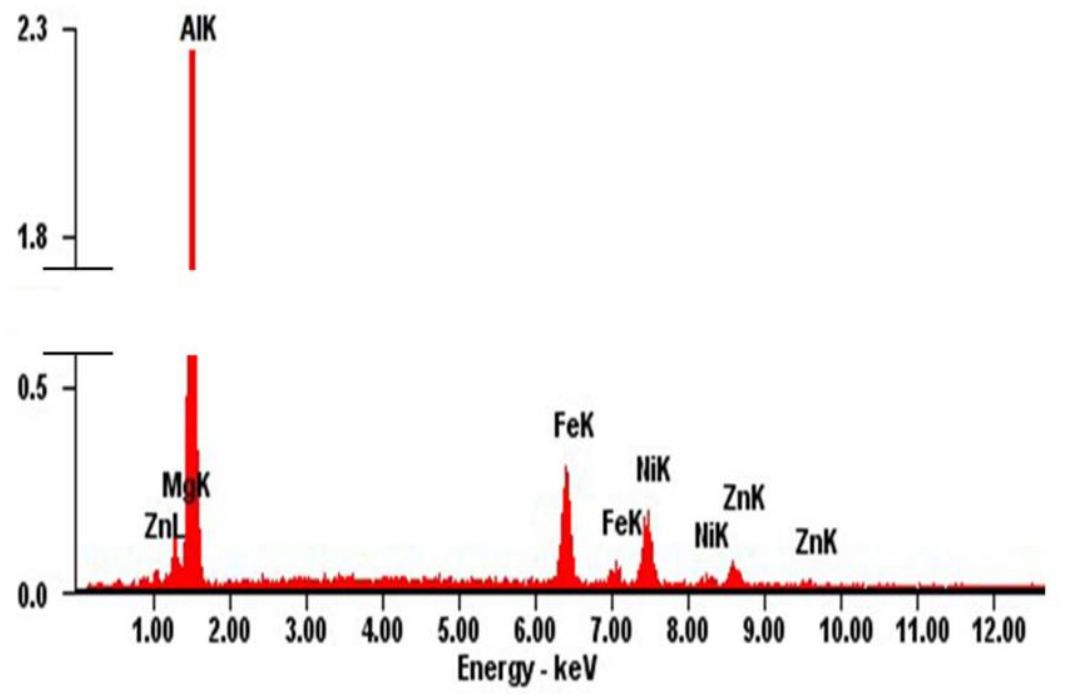

(e)

Figure 2. SEM microstructure showing the dynamically recrystallized structure (a) and the intermetallic particles (b,d) in peripheral zone and the intermetallic particles in the center zone (c) of cross-section of the nickalin 2 rod after RSR. The EDS element analysis of the $\mathrm{Al}_{9} \mathrm{FeNi}$ phase (e). 
The TEM results testify that, in the deformed region, the rod has a well-developed subgrain structure resulting from polygonization. The subgrains are mainly equiaxial and sized 2 to $6 \mu \mathrm{m}$. Along the subgrain boundaries there are disk- or stick-shaped (up to 1-5 $\mu \mathrm{m}$ ) $\mathrm{Al}_{9} \mathrm{FeNi}$ intermetallics of the crystallization origin. Globular and stick-shaped secondary phases have been found inside the subgrains. According to electron diffraction pattern, equiaxial nanoparticles 30 to $75 \mathrm{~nm}$ in diameter are the metastable $\mathrm{Al}_{3} \mathrm{Zr}$ phase with an ordered cubic lattice $\mathrm{L}_{2}$ (Figure $3 \mathrm{a}, \mathrm{b}$ ). These dispersoids result from hot deformation. Sticks with a diameter of $5 \mathrm{~nm}$ and a length ranging between 50 and $100 \mathrm{~nm}$ (separate large particles reach a diameter of $20 \mathrm{~nm}$ and a length of $250 \mathrm{~nm}$ (Figure 3c,d)), belong to the $\mathrm{MgZn}$ 2 phase precipitating from the supersaturated Al solid solution during cooling after RSR.

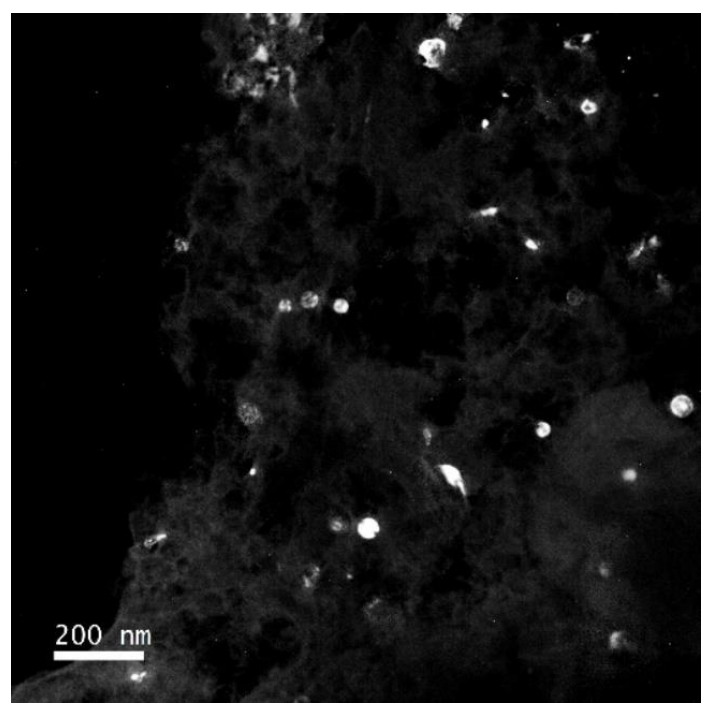

(a)

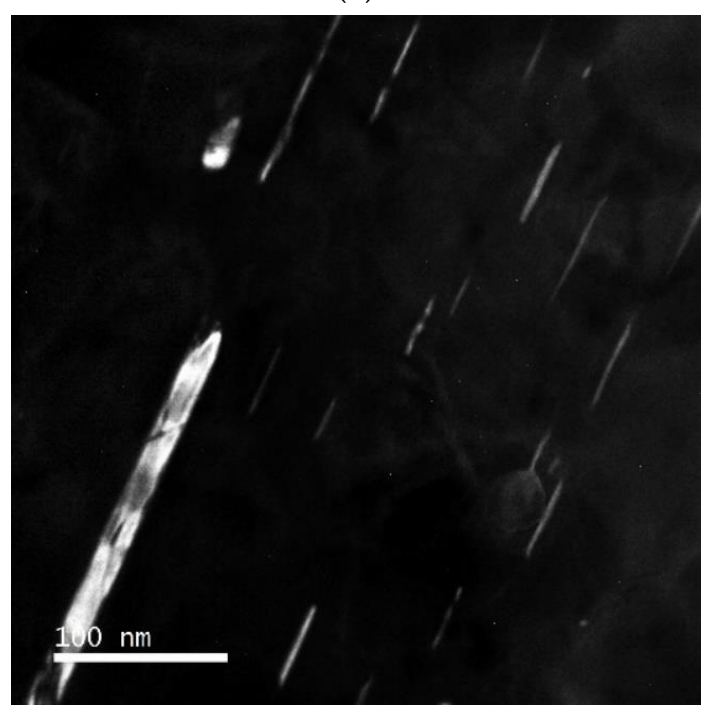

(c)

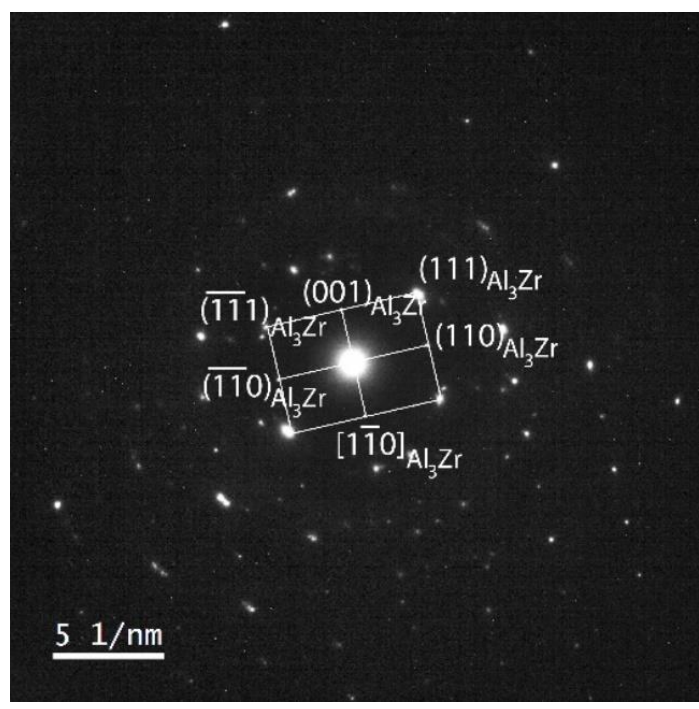

(b)

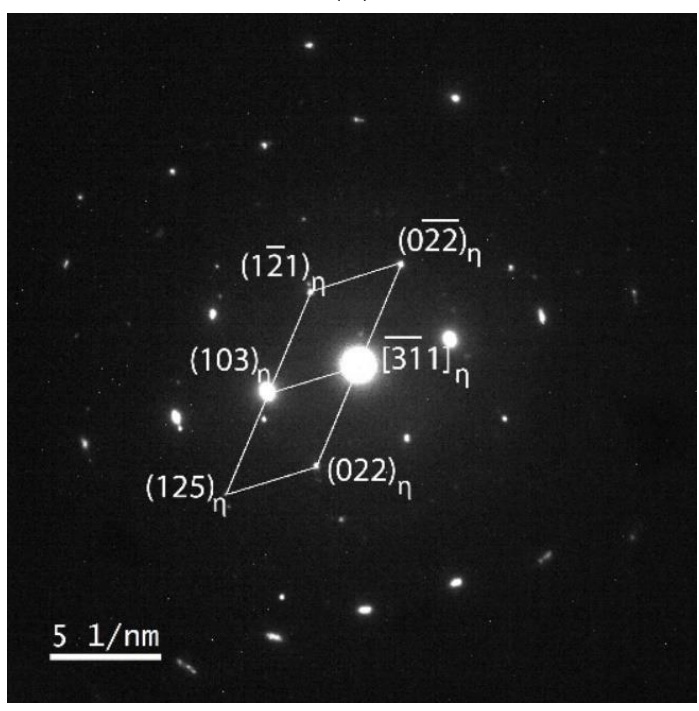

(d)

Figure 3. TEM dark-field images (a,c) and electron diffraction pattern $(\mathbf{b}, \mathbf{d})$ of intermetallic particles corresponding to the $\mathrm{Al}_{3} \mathrm{Zr}(\mathbf{a}, \mathbf{b})$ and $\mathrm{MgZn}_{2}(\mathbf{c}, \mathbf{d})$ phases in the nickalin 2 rod after RSR.

\subsection{Structure and Phase Composition after HPT}

The Al-Zn-Mg-Fe-Ni alloy in two structural states (nickalin 1 and nickalin 2) discussed in Section 3.1 was taken as macrocrystalline analogs for HPT specimens. The evolution of the structural and phase transformations in nickalin 1 and nickalin 2 was studied on 
specimens after HPT with different strains by varying the number of anvil revolutions $n=5,10$, and 15 ( $\varepsilon=6.0,6.7$, and 7.1 respectively). Microhardness was measured in order to characterize the uniformity of their structure along the specimen radius. It follows from the measurements that microhardness variation from the edge to the center does not exceed $150 \mathrm{MPa}$. However, in order to compare correctly the structure and phase composition of the specimens produced with different numbers of revolutions, all the TEM studies were performed on foils cut from the mid-radius region.

As a result of deformation, coarse eutectic aluminides in nickalin 1 become fragmented, they break into particles sized $\sim 1-2 \mu \mathrm{m}$. The $\mathrm{Al}$ matrix for $n=5$ and 10 is represented by a fragmented structure with grain/subgrain diffusion boundaries and a nonuniform contrast inside the grains/subgrains, which is caused by a high level of internal stresses (Figure 4a). Fragmentation increases with the amount of strain and, according to the results of the quantitative analysis of the EDS element analysis, the average size of the grain/subgrain ranges from 120 to $160 \mathrm{~nm}$ at $n=10$, with only $20 \%$ of them being larger than $200 \mathrm{~nm}$. At $n=15$, mainly high-angle boundaries (HABs) are formed in the structure, this being evidenced by the annular electron diffraction pattern with numerous discretely located point-like reflections (Figure $4 \mathrm{~b}$ ). The main array of grains/subgrains retains the strain-induced contrast, but in triple joints there are small (20 to $30 \mu \mathrm{m}$ ) dislocation-free grains formed through dynamic recrystallization. This mixed two-level structure decreases the average grain/subgrain size to the nanoscale $(\sim 100 \mathrm{~nm})$.

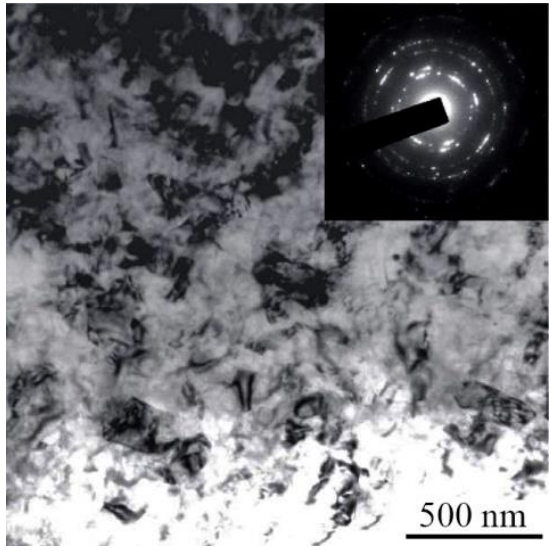

(a)

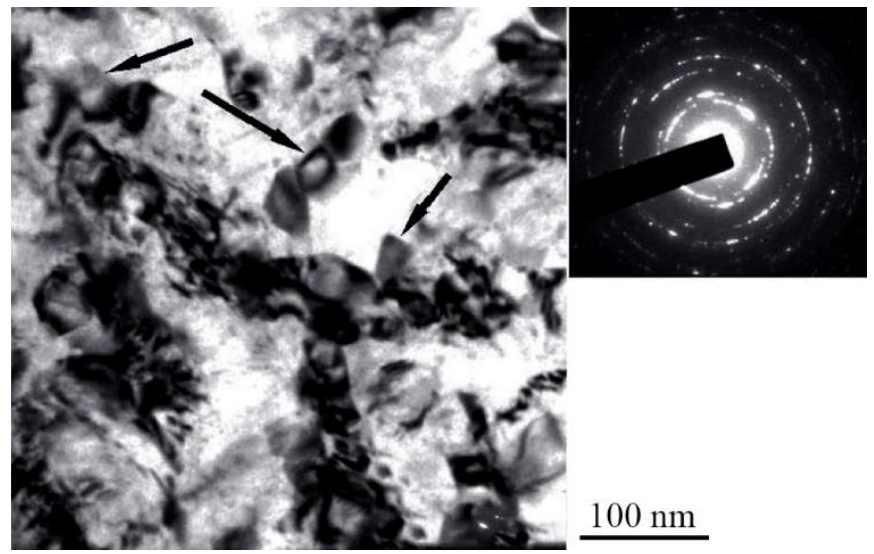

(b)

Figure 4. TEM microstructure showing the deformation structure of the nickalin 1 after HPT, $n=5$ (a) and $n=15$ (b).

The phase composition of nickalin 1 changes with the amount of strain. When $n=5$ and 10, the volume fraction of the particles of the secondary T-phase decreases due to their deformation dissolution, and when $n=15$, there appears a strain-induced Al solid solution supersaturated with zinc and magnesium.

The five-revolution deformation nickalin 2 results in significant fragmentation of the polygonized structure of the alloy. When $\varepsilon=6.0$, there appear variously sized subgrains, irregularly shaped or elongated. Most of them $(\sim 80 \%)$ have a size ranging from 50 to $250 \mathrm{~nm}$, with separate large subgrains having a size of up to $500 \mathrm{~nm}$ (Figure 5a,b). The annular character of the electron diffraction patterns with diffuse reflexes and the analysis of the dark-field images of the microstructure demonstrate that the fragments are separated by both high- and low-angle boundaries (LABs), Figure 5c. Deformation changes the morphology and average size of intermetallic particles. Fragmentation of $\mathrm{Al}_{9} \mathrm{FeNi}$ particles occurs, their characteristic size decreases to $0.6-3.5 \mu \mathrm{m}$, and the diameter of the $\mathrm{Al}_{3} \mathrm{Zr}$ dispersoid precipitates also decreases to $30-40 \mathrm{~nm}$, possibly, due to partial dissolution during HPT, as was noted in [30]. 


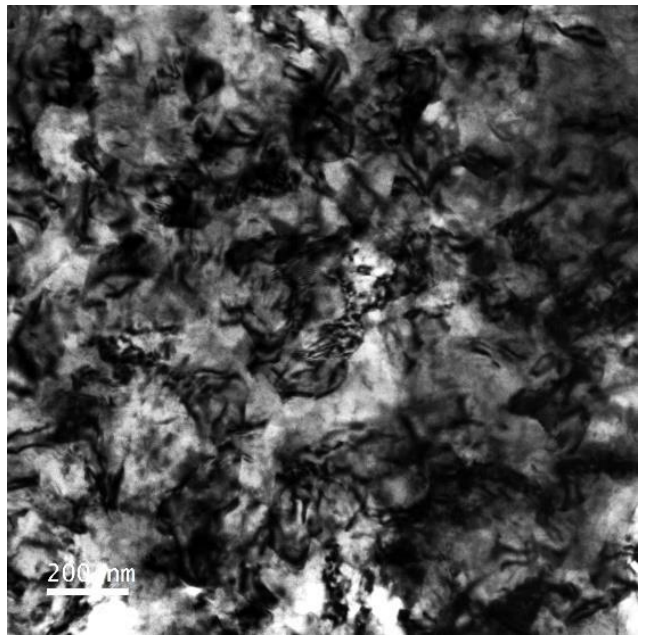

(a)

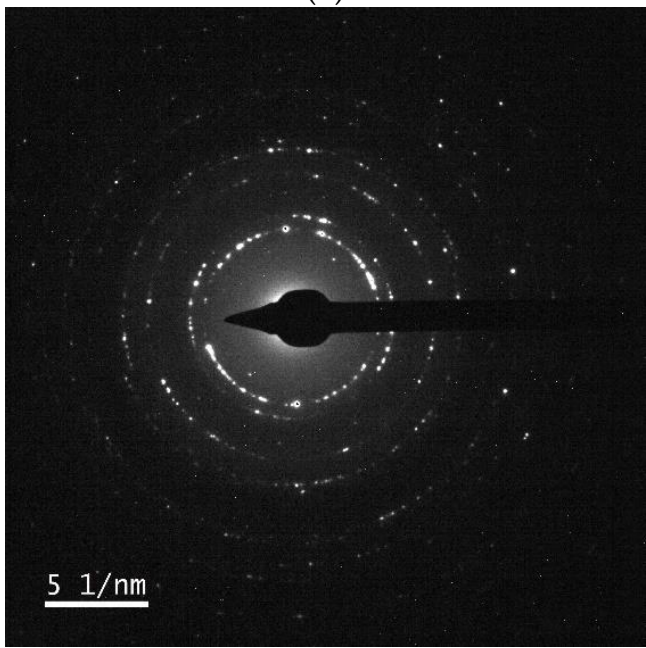

(c)

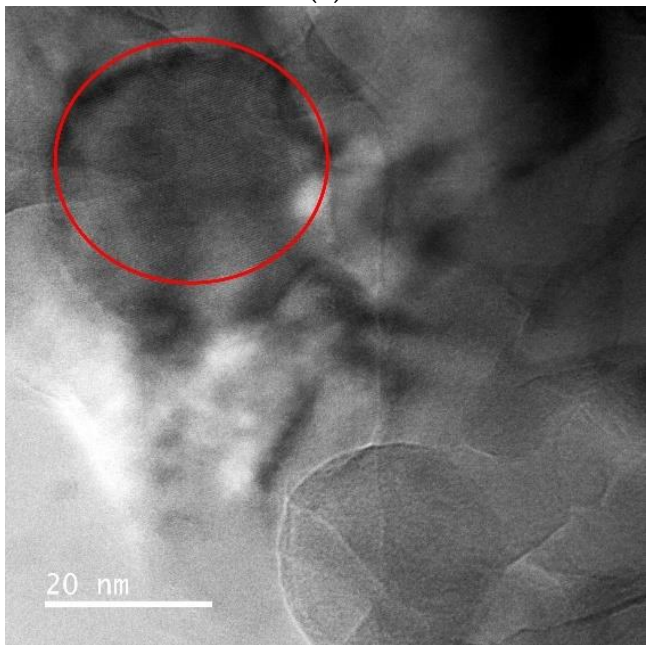

(e)

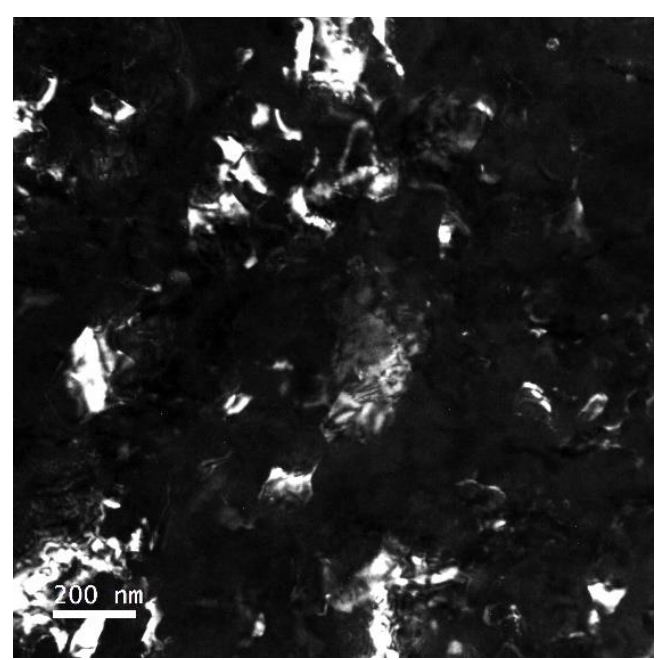

(b)

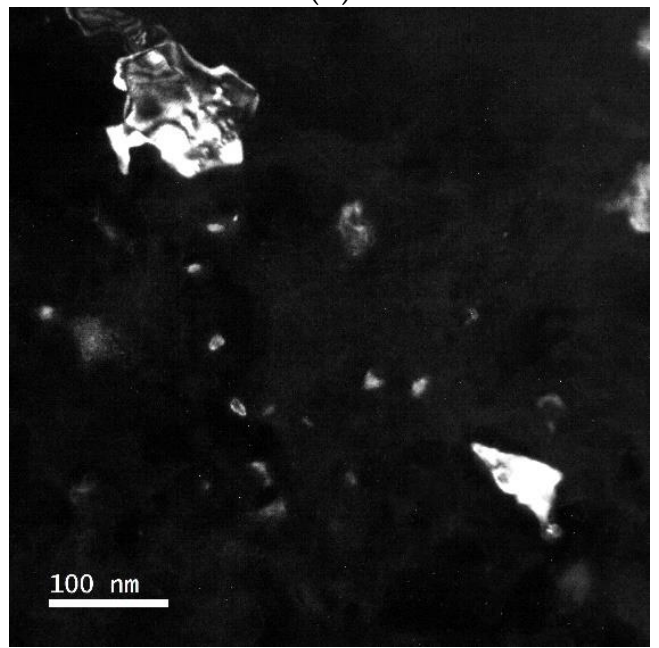

(d)

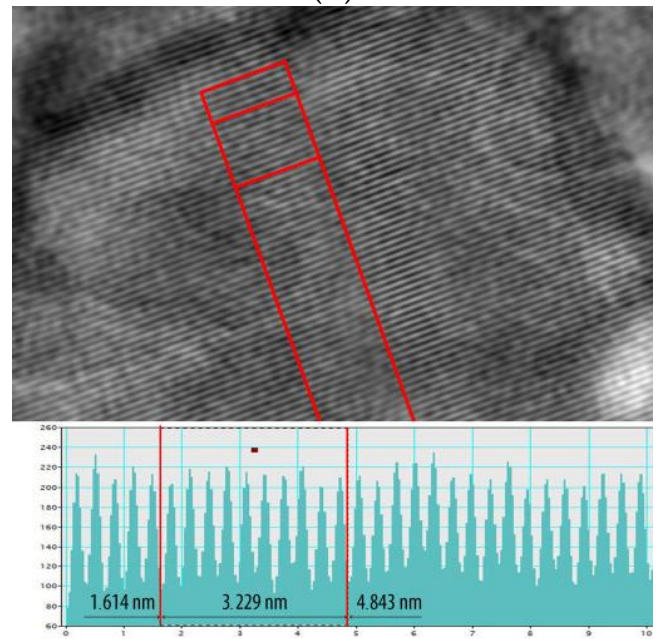

(f)

Figure 5. TEM bright-field image (a), dark-field images (b,d) and electron diffraction pattern (c) of deformation structure $(\mathbf{a}-\mathbf{c})$ and intermetallic particles corresponding to the $\mathrm{T}(\mathbf{d}, \mathbf{e})$ phase in the nickalin 2 after HPT, $n=5$. (e) HRTEM image of T-phase $(\mathrm{d}=0.3229 \mathrm{~nm})$ particle. (f) An enlarged region of the particle shown in $(\mathbf{e}, \mathbf{f})$ and intensity histogram.

The analysis of the bright-field and dark-field images has shown that five-revolution deformation causes a complete dissolution of the zinc-magnesium phases, with the ap- 
pearance of a strain-induced $\mathrm{Al}$ solid solution supersaturated with zinc and magnesium. On the other hand, the HPT process causes the decomposition the supersaturated solid solution and the formation of dispersed particles sized up to $20 \mathrm{~nm}$ along the boundaries of the matrix fragments (Figure 5d). The high dispersion and low volume fraction of these precipitates prevent them from being identified by electron microdiffraction patterns.

The calculation of the interplanar distances by the direct resolution of the particle lattice allows us to conclude that they are T-phase precipitates $\left(\mathrm{d}_{(420) \mathrm{T}}=0.3222 \mathrm{~nm}\right.$, Figure $\left.5 \mathrm{e}, \mathrm{f}\right)$.

A characteristic feature of the structural state for $n=10$ is the formation of a banded structure consisting of 40-120 nm grains/subgrains separated by low-angle and high-angle boundaries (Figure 6a-c).

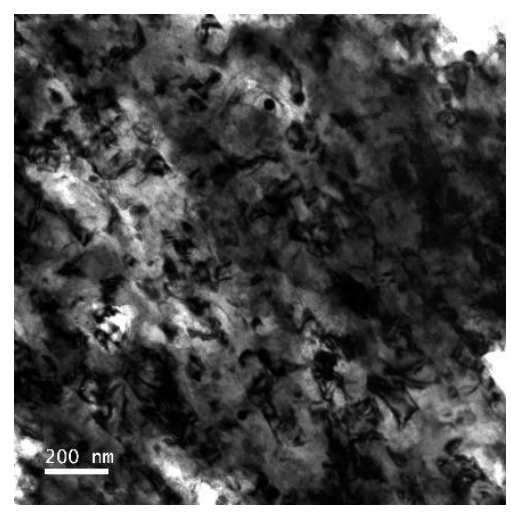

(a)

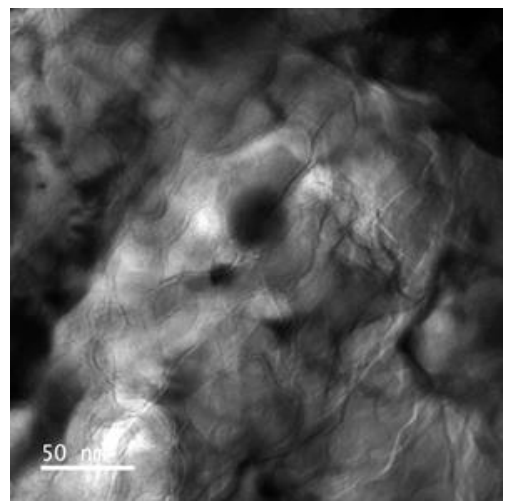

(d)

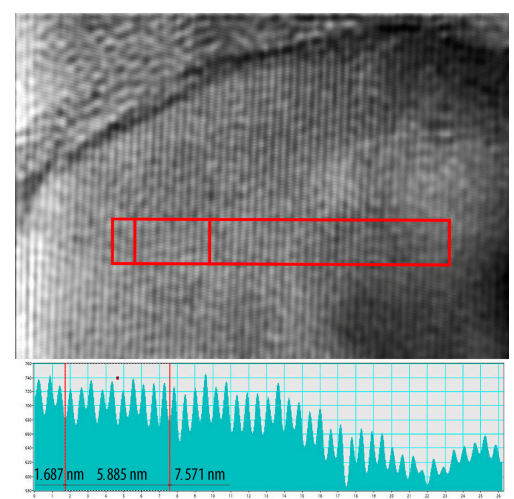

(g)

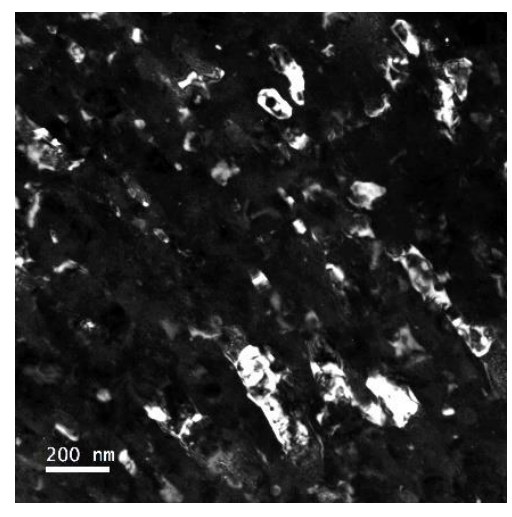

(b)

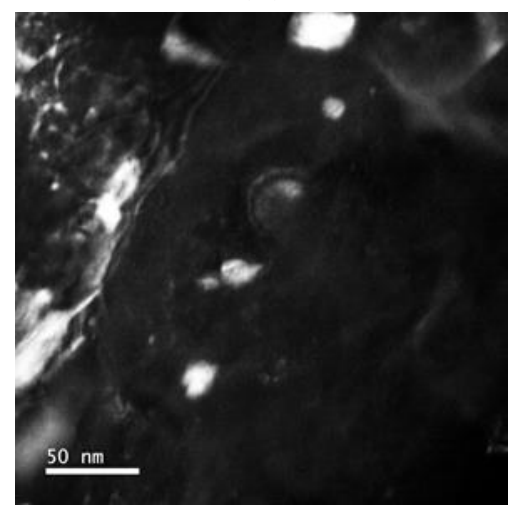

(e)

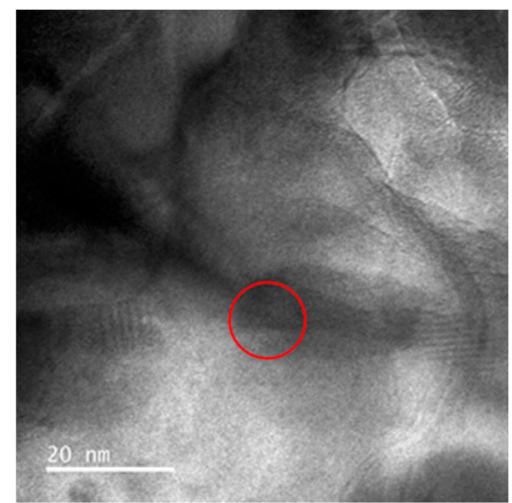

(h)

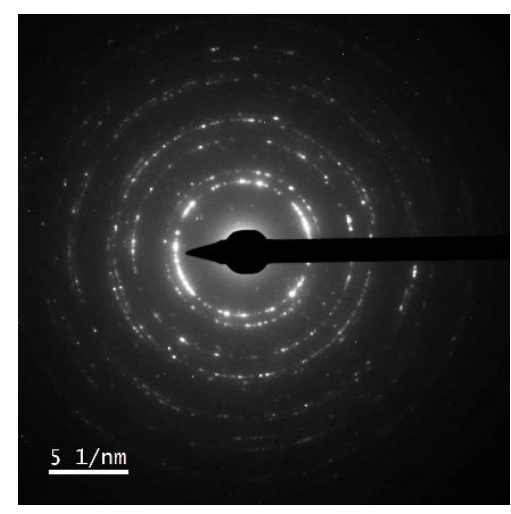

(c)

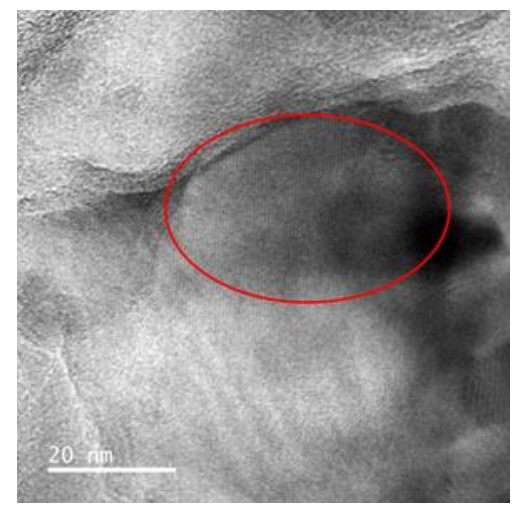

(f)

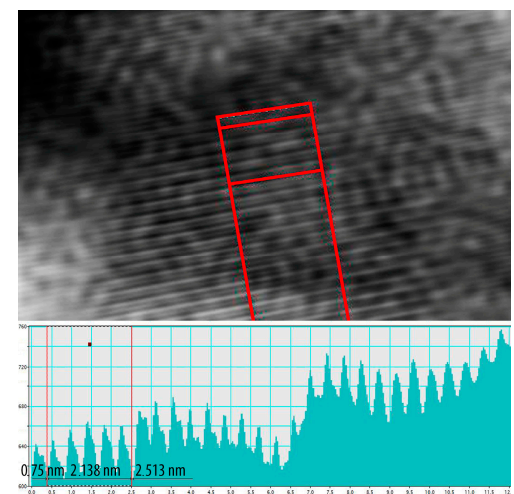

(i)

Figure 6. TEM bright-field image (a,d), dark-field images (b,e), and electron diffraction pattern (c) deformation structure $(\mathbf{a}-\mathbf{c})$ and intermetallic particles corresponding to the T and $\eta(\mathbf{d}-\mathbf{g})$ phases in the nickalin 2 after HPT, $n=10$. HRTEM images of $\mathrm{T}(\mathrm{d}=0.5882 \mathrm{~nm})(\mathbf{f}, \mathbf{g})$ and $\eta(\mathrm{d}=0.4276 \mathrm{~nm})(\mathbf{h}, \mathbf{i})$ phases particles. $(\mathbf{g}, \mathbf{i})$ Enlarged regions of the particle shown in $(\mathbf{f}, \mathbf{h})$ and intensity histograms. 
According to the HRTEM data, the growing amount of strain initiates the decomposition of the supersaturated solid solution (Figure $6 \mathrm{~d}$,e); besides precipitates along the boundaries of T-phase fragments sized 15 to $40 \mathrm{~nm}\left(\mathrm{~d}_{(210) \mathrm{T}}=0.5883 \mathrm{~nm}\right.$, Figure $\left.6 \mathrm{f}, \mathrm{g}\right)$, more dispersed 10 to $20 \mathrm{~nm}$ equiaxial particles of the $\eta$ or $\eta^{\prime}$-phase $\left(\mathrm{d}_{(100) \eta^{\prime}}=0.4295 \mathrm{~nm}\right.$, $\mathrm{d}_{(002) \eta}=0.4283 \mathrm{~nm}$, Figure $\left.6 \mathrm{~h}, \mathrm{i}\right)$ are detectable inside the grains/subgrains. As the amount of strain increases, large $\mathrm{Al}_{9} \mathrm{FeNi}$ inclusions continue decreasing in size to 1-1.5 $\mu \mathrm{m}$, with individual fragments being nanosized; the $\mathrm{Al}_{3} \mathrm{Zr}$ distribution density remains practically unchanged.

The maximum deformation with 15 revolutions causes results in a further refinement of the submicrocrystalline structure, this being clearly visible from the dark-field image (Figure 7a). The grains/subgrains size distribution becomes more uniform, with the average size reaching 30 to $90 \mathrm{~nm}$, i.e., a nanostructured state is formed and grain misorientation angles increase, as follows from the annular electron diffraction pattern with numerous discrete point-like reflections (Figure $7 \mathrm{~b}$ ). Similarly to the structure of HPT nickalin 1, when $n=15$, in the structure of HPT nickalin 2, in the triple joints and on the matrix-intermetallics interphase boundaries, there also appear recrystallized grains, i.e., two structure refinement processes occur simultaneously: fragmentation and in-situ recrystallization. On the background of the nanostructured matrix, there are intermetallic particles of different shapes and sizes, close to those found in HPT nickalin 2 after $n=10$. In follows from the results of electron diffraction patterns and direct lattice resolution, they belong to four phases: $\mathrm{Al}_{9} \mathrm{FeNi}, \mathrm{Al}_{3} \mathrm{Zr}$, $\mathrm{T}$, and $\eta$.

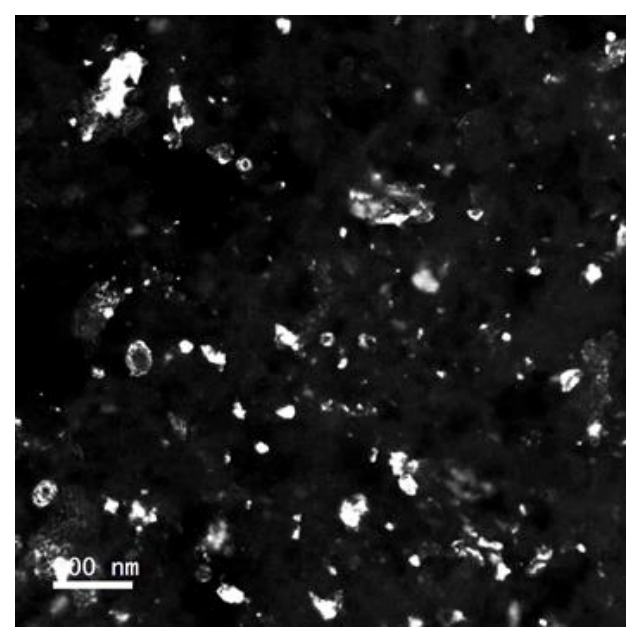

(a)

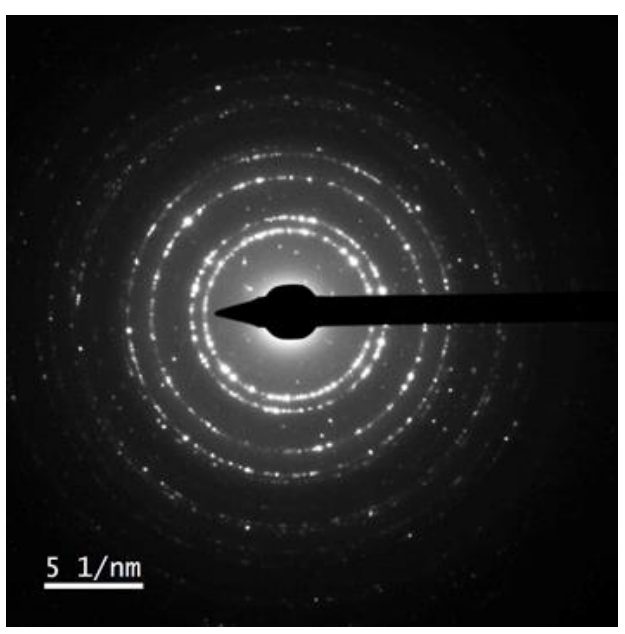

(b)

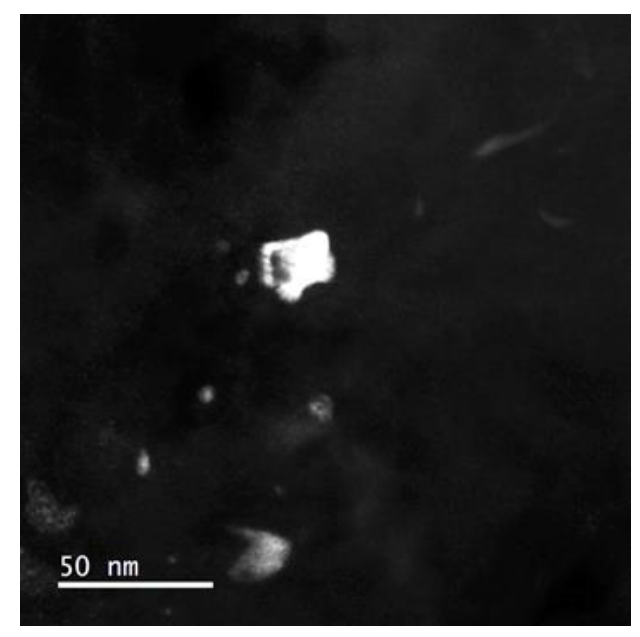

(c)

Figure 7. TEM dark-field images $(\mathbf{a}, \mathbf{c})$ and electron diffraction pattern $(\mathbf{b})$ of deformed structure in the nickalin2 after HPT, $n=15$. 
Thus, complex deformation processing, namely RSR + HPT, yields an aluminummatrix composite reinforced with dispersed intermetallics of different natures.

\subsection{Hardness and Mechanical Properties of Nickalin}

The size characteristics of the alloy microstructure before and after HPT are vividly demonstrated by hardness testing. It has been found that nanostructured HPT nickalin 2 has a microhardness of 1800 to $2000 \mathrm{MPa}$, which by a factor of 1.7-1.8 exceeds that measured at the mid-radius of the RSR rod. Nanocrystalline nickalin 1 produced by HPT with the same amount of strain $(n=15)$ also has double microhardness relative to the macrocrystalline analog.

The procedure discussed in Section 2 was used to measure the mechanical properties of nanocrystalline alloys that were obtained by HPT with $n=15$. Typical stress-strain diagram is shown in Figure 8. The average values obtained by measuring the mechanical properties of two samples are shown in Table 2 in comparison with the properties of macrocrystalline analogs. Let us compare how mechanical characteristics of the cast alloy change depending on the type deformation processing. According to the Table 2, RSR increases the tensile yield strength (YS) of the cast alloy from 240 to $264 \mathrm{MPa}$. The combined treatment (RSR + HPT) causes an additional increase in YS to $628 \mathrm{MPa}$, i.e., 2.8 times relative to YS of an ingot and 1.8 times relative to ultimate tensile strength (UTS) of an ingot. It follows from the data that the strength properties of the nanostructured alloys after HPT and the combined treatment (RSR + HPT), exceed those for macrocrystalline analogs (an ingot, a rod). Tensile yield strength increases by a factor of 2.0-2.4 and ultimate tensile strength increases by a factor of 1.3-1.5. The different mechanical characteristics of nickalin 1 and nickalin 2 after HPT are determinates by the different structure, phase composition, and different structural strengthening mechanisms.

The higher values of the strength properties of HPT + RSR nickalin $2(\mathrm{YS}=628 \mathrm{MPa}$, UTS $=640 \mathrm{MPa})$ then the strength properties of nickalin $1(\mathrm{YS}=450 \mathrm{MPa}$, UTS $=470 \mathrm{MPa}$ ) are associated with a more dispersed structure and additional contribution of the strengthening from the dispersed particles of the secondary phase. The hardening mechanisms are described more detail in Section 4.

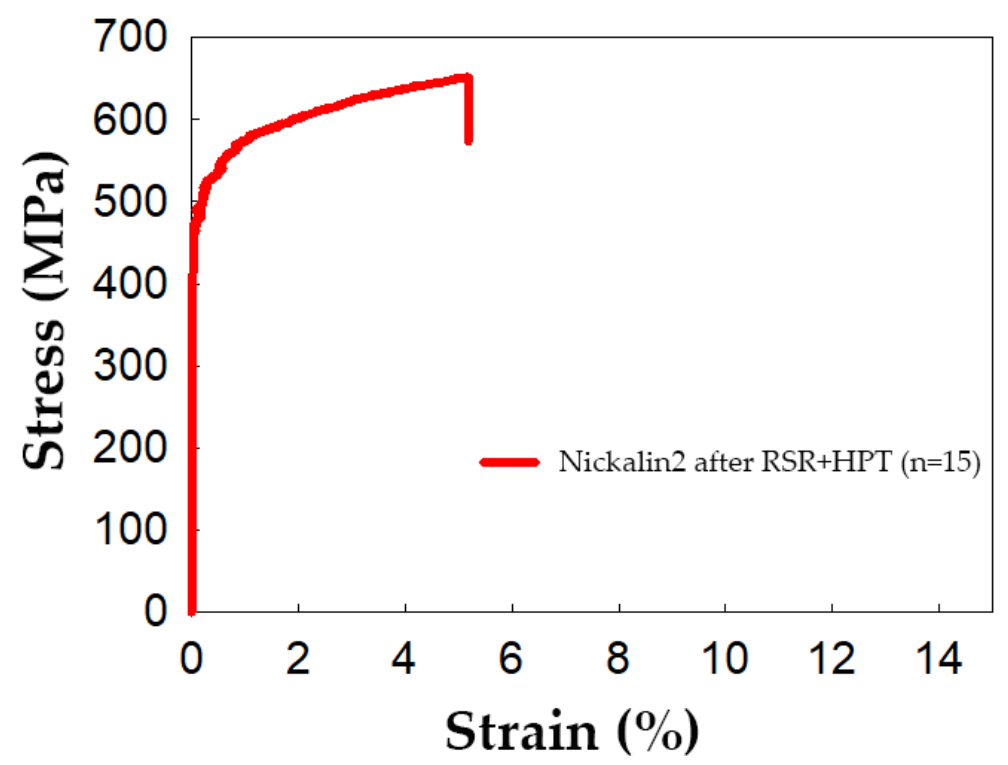

Figure 8. Stress-strain diagram of the Nickalin 2 after RSR + HP $(n=15)$. 
Table 2. Uniaxial tensile tests for the nickalins after different treatments.

\begin{tabular}{cccc}
\hline Condition & $\begin{array}{c}\text { Tensile Yield } \\
\text { Strength, MPa }\end{array}$ & $\begin{array}{c}\text { Ultimate Tensile } \\
\text { Strength, MPa }\end{array}$ & Elongation, \% \\
\hline $\begin{array}{c}\text { Ingot after } \\
\text { homogenization } \\
\text { Rod after RSR, two } \\
\text { passes, (mid-radius) } \\
\text { Nickalin 1 (ingot) } \\
\text { after HPT (n=15) }\end{array}$ & 220 & 350 & 6 \\
$\begin{array}{c}\text { Nickalin 2 (rod) after } \\
\text { RSR+ HP }(n=15)\end{array}$ & 450 & 436 & 70 \\
\hline
\end{tabular}

\section{Discussion}

This study shows the evolution of structural and phase transformations in the Al-Zn$\mathrm{Mg}-\mathrm{Fe}-\mathrm{Ni}$ alloy with different histories during severe plastic deformation. An ingot after homogenization annealing (nickalin 1) and a rod after RSR (nickalin 2) served as initial specimens for HPT.

The microstructural studies, including SEM and high resolution TEM have shown that the structure formation mechanisms in common during HPT are as follows.

HPT results in an intensive refinement of the Al matrix structure to the nanocrystalline state. The formation of a dispersed structure follows two mechanisms: fragmentation at a true strain $\varepsilon=6.0$ to $6.7(n=5,10)$ and in-situ low-temperature dynamic recrystallization at $\varepsilon=7.1(n=15)$. The fragmented structure is characterized by the diffusion contrast of HABs, high dislocation density and the presence of LABs inside the grains/subgrains. The mixed structure consisting of deformation-induced fragments with LABs and HABs and recrystallized grains separated by HABs is bimodal, and this provides the best combination of strength and plastic properties. The average grain/subgrain size in HPT nickalin 1 is $100 \mathrm{~nm}$, and it is $60 \mathrm{~nm}$ in HPT nickalin 2. Such nanostructures exhibit high hardness $\mathrm{H}_{\mathrm{V}}=2000$ to $2600 \mathrm{MPa}$. The strengthening mechanisms for various materials after HPT were repeatedly proved in experiments reported in [19-21,35-37]; namely, according to the Hall-Petch equation, grain-boundary strengthening increases intensely, and the abundance of structural defects is responsible for the high value of the dislocation strengthening component.

The quantitative data obtained by TEM suggest that, during $\mathrm{HPT}, \mathrm{Al}_{9} \mathrm{FeNi}$ eutectic aluminides crash into fragments whose size becomes commensurate with the secondary phases; the fragments are uniformly distributed in the matrix volume. If the $\mathrm{Al}_{9} \mathrm{FeNi}$ particles were micron-sized ( 2 to $5 \mu \mathrm{m}$ ) in the macrocrystalline analogs (the ingot and the rod), their size does not exceed $1 \mu \mathrm{m}$ after HPT, and there appear nanoparticles when $n=15$.

According to the TEM data, the phase composition of the alloy changes during HPT, the sequence and kinetics of the phase transformations being dependent on the history of the macrocrystalline analogs. As was noted in Section 3.2, during HPT of nickalin 1, at $\varepsilon=7.1$, a supersaturated $\mathrm{Al}$ solid solution is formed due to the strain-induced dissolution of the secondary T-phase. Additional solid-solution hardening combined with grain-boundary and dislocation components provides high hardness to the material, $\mathrm{H}_{\mathrm{V}}=2500 \mathrm{MPa}$.

Additionally, the formation of a supersaturated Al solid solution during HPT can be proved by the results obtained during subsequent post-deformation heat treatment [31,32]. According to this data, low-temperature annealing $\left(\mathrm{T}=120-160^{\circ} \mathrm{C}\right)$ is accompanied by the decomposition of the supersaturated $\mathrm{Al}$ solid solution, which occurs simultaneously with the thermal softening of the alloy. Dispersed particles of the $\mathrm{T}$ and $\eta$ strengthening phases precipitate as a result of artificial aging. Due to aging, the hardening achieved under HPT remains high. The presence of the nanostructure significantly reduces the duration of the maximum effect of $\mathrm{Al}$ solid solution decomposition from 3-6 h to $0.5-1.0 \mathrm{~h}$. Consequently, the thermal deformation processing of nickalin 1 forms a two-phase material consisting of a nanostructured supersaturated $\mathrm{Al}$ solid solution and micron-sized $\mathrm{Al}_{9} \mathrm{FeNi}$ aluminides of eutectic origin. 
The phase transformations in nickalin 2 under HPT are more diverse. Prior to RSR deformation, the rod had a multiphase composition comprising, besides the $\mathrm{Al}$ matrix and $\mathrm{Al}_{9} \mathrm{FeNi}$ aluminides, the $\mathrm{Al}_{3} \mathrm{Zr}$ and $\mathrm{MgZn}_{2}$ secondary phases. The conditions of their formation are described in Section 3.1.

Under HPT these phases alter their morphologies and sizes owing to two opposite processes induced by SPD, namely the strain-induced dissolution of intermetallics and the kinetic strain aging of the Al matrix. As a result of HPT $(n=5, \varepsilon=6.0)$, the $\mathrm{MgZn}_{2}$ phase dissolves with the accumulation of mobile dislocations, which, while moving, cut the particles and transfer magnesium and zinc atoms into the Al solid solution. An increase in true strain to $\varepsilon=6.7-7.1(n=10-15)$ intensifies the subsequent decomposition of the supersaturated solid solution under kinetic strain aging. This inversion of the matrix composition results in that the stick-shaped particles of the $\eta$ phase disappear and that dispersed $(40 \mathrm{~nm}$ ) globular precipitates of the T-phase appear along the grain/subgrain boundaries of the Al matrix.

One of the possible reasons for the heterogeneous nucleation of secondary phases at the grain/subgrain boundaries is the appearance of abnormal grain-boundary segregations of the atoms of alloying elements under HPT, whose formation was proved theoretically [38] and experimentally [37,39]. In this connection, the precipitation of the secondary phases along the grain boundaries is easier, and they become dominant. Besides, the size of the particles and their discrete arrangement along the boundaries of the nanocrystalline structure does not decrease the alloy plasticity. Note that a distinctive feature of the morphology of the zinc-magnesium phases precipitating at low temperature under SPD is their globular shape.

As deformation with $n=10$ increases $(\varepsilon=6.7)$, strain aging further develops, inside the grains/subgrains of the Al matrix there appear nanosized precipitates of the $\eta^{\prime}$ phase, the quantity of which increases with the amount of strain, $\varepsilon=7.1(n=15)$. The reasons for the alternation and competition of the $\mathrm{T}$ and $\eta^{\prime}$ phase precipitations under dynamic aging can be explained by referring to the results reported in [40], where it was found by atom probe tomography that, at an early stage of aging, clusters form in the Al-Zn-Mg-Cu alloy, with different $\mathrm{Zn} / \mathrm{Mg}$ atomic ratios depending on $\mathrm{Zn}$ content in the supersaturated solid solution. With the atomic ratio $\mathrm{Zn} / \mathrm{Mg}<1.3$, the clusters transform into the T-phase, and when $\mathrm{Zn} / \mathrm{Mg}>1.3$ they turn into the $\eta^{\prime}$-phase. As a result of the nonuniform deformation of the specimen volumes during HPT, the local regions of the strain-induced supersaturated Al solid solution have different combinations of alloying element concentrations. Accordingly, clusters appear with different $\mathrm{Zn} / \mathrm{Mg}$ atomic ratios, which serve as centers for heterogeneous nucleation of strengthening phase precipitates.

The possibility of the occurrence of the above phase transformations during lowtemperature SPD stems from a several orders of magnitude increase in the atomic diffusion coefficients of the alloying elements in the Al matrix due to excess vacancy concentration [41,42]. Besides, the formation of a strain-induced supersaturated solid solution may be due to the pinning and transfer of alloying element atoms on dislocations during their migration.

The XRD analysis confirms the TEM results and based on the change in the matrix lattice parameter before and after HPT from $a=0.4064 \pm 0.0001 \mathrm{~nm}(n=0)$ to $a=0.4067 \pm$ $0.0002 \mathrm{~nm}(n=15)$.

The analysis of the structural and strength characteristics of the Al- $\mathrm{Zn}-\mathrm{Mg}-\mathrm{Fe}-\mathrm{Ni}$ alloy after HPT shows their interrelation. The difference between the phase compositions of nickalin 1 and nickalin 2 causes the different mechanical characteristics of these materials due to the action of different structural strengthening mechanisms. The total strength of nickalin 1 (YS $=450 \mathrm{MPa}$, UTS $=470 \mathrm{MPa})$ is the sum of grain-boundary strengthening by the Hall-Petch mechanism, dislocation strengthening resulting from high dislocation density, and solid-solution strengthening. The higher values of the strength properties of HPT nickalin 2 (YS = $628 \mathrm{MPa}$, UTS $=640 \mathrm{MPa})$, which is a multiphase nanocomposite, are caused by the additional contribution of dispersion strengthening from the dispersed 
particles of the secondary phase through the Orowan mechanism, as well as by the greatest contribution of the grain-boundary mechanism to the total strength due to the formation of smaller (half-size) grains. The comparison of the obtained strength characteristics with the corresponding properties of the Al-Zn-Mg-Fe-Ni alloy after four RSR cycles (YS $=410 \mathrm{MPa}$, UTS = $430 \mathrm{MPa}$ ) [33] shows the advantage of using combined deformation processing. Besides, the mechanical properties are comparable with those of other 7xxx series alloys after SPD and aging. For example, YS $=525 \mathrm{MPa}$, UTS $=547 \mathrm{MPa}$ in the 7050 alloy after six ECAP passes (route Bc) [27] and YS = 520 MPa in the Al-Zn-Mg alloy after ECAP and aging [28].

\section{Conclusions}

1. The effect of combined deformation processing (RSR + HPT) on the structural and phase transformations and mechanical properties of the $\mathrm{Al}-\mathrm{Zn}-\mathrm{Mg}-\mathrm{Cu}-\mathrm{Fe}-\mathrm{Ni}$ eutectic alloy has been studied. It has been found that severe plastic deformation is accompanied by the formation of a high-strength $(\mathrm{Hv}=2000$ to $2600 \mathrm{MPa})$ aluminum-matrix composite reinforced with dispersed intermetallic compounds of different origins.

2. With the application of high-resolution TEM methods, the morphological and size characteristics of the $\mathrm{Al}$ matrix, $\mathrm{Al}_{9} \mathrm{FeNi}$ eutectic aluminides, and secondary phases has been determined. The mixed nanostructure of the matrix is formed by two mechanisms: fragmentation and continuous dynamic recrystallization; the average grain/subgrain size changes from 60 to $100 \mathrm{~nm}$ depending on the alloy history. Eutectic aluminides break down into micron-sized fragments and become uniformly distributed in the volume; the strengthening phases precipitate in the form of globules on the grain boundaries and inside the matrix grains.

3. The sequence of phase transformations induced by HPT, namely strain-induced dissolution of secondary phases and kinetic strain aging of the Al matrix, has been identified, as well as their evolution at different amounts of strain. The phase transformations induced by HPT are an additional channel of elastic energy relaxation. It has been demonstrated that the strain-induced dissolution of the initial $\mathrm{Mg}_{2} \mathrm{Zn}$ phase and the formation of a supersaturated Al solid solution occur at $n=5$. At $n=10-15$ it is replaced by the decomposition of $\mathrm{Al}$ solid solution and the appearance of nanosized strengthening metastable $\mathrm{T}$ and $\eta^{\prime}$ phases.

4. The mechanical properties of the nanostructured composite $(\mathrm{YS}=628 \mathrm{MPa}$, UTS = $640 \mathrm{MPa}$ ) have been determined; their comparison with the properties of $7 x x x$ series alloys after SPD proves the expediency of using combined deformation processing for Al-Zn-Mg-Fe-Ni alloys.

Author Contributions: Conceptualization, methodology, and writing, I.B.; TEM investigation and writing, D.R.; SEM investigation, I.S.; TEM investigation, A.P.; Measurement of properties, T.A. and E.B. All authors have read and agreed to the published version of the manuscript.

Funding: This research was funded by the Ministry of Education and Science of the Russian Federation (a State Task on theme «Struktura», number AAAA-A18-118020190116-6).

Institutional Review Board Statement: Not applicable.

Informed Consent Statement: Not applicable.

Data Availability Statement: Data sharing not applicable.

Acknowledgments: The electron microscopic studies were performed at the Center of Collaborative Access Test Center of Nanotechnologies and Advanced Materials, Institute of Metal Physics, Ural Branch, Russian Academy of Sciences, Ekaterinburg, Russia).

Conflicts of Interest: The authors declare no conflict of interest.

\section{References}

1. Addzadeh, H.; Baharvandi, H.R.; Shirvani Moghaddam, K. Comparing the effect of processing temperature on microstructure and mechanical behavior of $\left(\mathrm{ZrSiO}_{4}\right.$ or $\left.\mathrm{TiB}_{2}\right)$ /aluminum composites. Mater. Sci. Eng. A 2008, 498, 53-58. [CrossRef] 
2. Abrosimova, G.E.; Aronin, A.S. Effect of the concentration of a rare-earth component on the parameters of the nanocrystalline structure in aluminum-based alloys. Phys. Solid. State 2009, 51, 1765-1771. [CrossRef]

3. Karbalaei, M.; Akbari, S.R.; Shirvani Moghaddam, K.; Baharvandi, H.R. Wear and friction behavior of nanosized $\mathrm{TiB}_{2}$ and $\mathrm{TiO}_{2}$ particle capture in matrix. Compos. Mater. 2015, 49, 3665-3681. [CrossRef]

4. Miracle, D.B. Metal matrix composites-From science to technological significance. Compos. Sci. Technol. 2005, 65, 2526-2540. [CrossRef]

5. Ma, Z.Y.; Tjong, S.C. High-temperature creep behaviour of SiC particulate reinforced Al-Fe-V-Si alloy composite. Mater. Sci. Eng. A 2000, 278, 5-15. [CrossRef]

6. Čadek, J.; Kuchařová, K.; Zhu, S.J. High temperature creep behaviour of an Al-8.5Fe-1.3V-1.7Si alloy reinforced with silicon carbide particulates. Mater. Sci. Eng. A 2000, 283, 172-180. [CrossRef]

7. Božić, D.; Vilotijević, M.; Rajković, V.; Gnjidić, Ž. Mechanical and Fracture Behaviour of a SiC-Particle-Reinforced Aluminum Alloy at High Temperature. Mater. Sci. Forum 2005, 494, 487-492. [CrossRef]

8. Kumara, J.; Singhb, D.; Kalsi, N.S.; Sharma, S.; Pruncu, C.I.; Pimenov, D.Y.; Rao, K.V.; Kapłonekh, W. Comparative study on the mechanical, tribological, morphological and structural properties of vortex casting processed, Al-SiC-Cr hybrid metal matrix composites for high strength wear-resistant applications: Fabrication and characterizations. J. Mater. Res. Technol. 2020, 9, 13607-13615. [CrossRef]

9. Belov, N.A. Quantitative phase analysis of the $\mathrm{Al}-\mathrm{Zn}-\mathrm{Mg}-\mathrm{Cu}-\mathrm{Ni}$ phase diagram in the region of compositions of high-strength nikalines. Russ. J. Non-Ferrous Met. 2010, 51, 243-249. [CrossRef]

10. Belov, N.A.; Alabin, A.N.; Sannikov, A.V.; Tabachkova, N.Y.; Deev, V.B. Effect of annealing on the structure and hardening of heat-resistant castable aluminum alloy AN2ZhMts. Metal. Sci. Heat Treat. 2014, 56, 353-358. [CrossRef]

11. Akopyan, T.K.; Belov, N.A. Approaches to the design of the new high-strength casting aluminum alloys of 7xxx series with high iron content. Non-Ferrous Met. 2016, 1, 20-26. [CrossRef]

12. Kim, Y.G.; Ko, Y.G.; Shin, D.H.; Lee, S. Effect of equal-channel angular pressing routes on high-strain-rate deformation behavior of ultra-fine-grained aluminum alloy. Acta Mater. 2010, 58, 2545-2554. [CrossRef]

13. Valiev, R.Z.; Langdon, T.G. Principles of equal-channel angular pressing as a processing tool for grain refinement. Prog. Mater. Sci. 2006, 51, 881-981. [CrossRef]

14. Shaeri, M.H.; Salehi, M.T.; Seyyedein, S.H.; Abutalebi, M.R.; Park, J.K. Microstructure and mechanical properties of Al-7075 alloy processed by equal channel angular pressing combined with aging treatment. J. Mater. Des. 2014, 57, 250-257. [CrossRef]

15. Segal, V.M. Engineering and commercialization of equal channel angular extrusion (ECAE). Mater. Sci. Eng. A 2004, 386, 269-276. [CrossRef]

16. Kulitskiy, V.; Malopheyev, S.; Mironov, S.; Kaibyshev, R. Grain refinement in an Al-Mg-Sc alloy: Equal-channel angular pressing versus friction-stir-processing. Mater. Sci. Eng. A 2016, 674, 480-490. [CrossRef]

17. Ning, Z.L.; Guo, S.; Cao, F.Y.; Wang, G.J.; Li, Z.C.; Sun, J.F. Microstructural evolution during extrusion and ECAP of a spraydeposited Al-Zn-Mg-Cu-Sc-Zr alloy. J. Mater. Sci. 2010, 45, 3023-3029. [CrossRef]

18. Yang, Y.; Zhao, Y.; Kai, X.; Zhang, Z.; Zhang, H.; Tao, R.; Chen, G.; Yin, H.; Wang, M. Effects of hot extrusion and heat treatment on microstructure and properties of industrial large-scale spray-deposited 7055 aluminum alloy. Mater. Res. Express 2018, 5. [CrossRef]

19. Zhu, Y.T.; Lowe, T.C.; Langdon, T.G. Performance and applications of nanostructured materials produced by severe plastic deformation. Scr. Mater. 2004, 51, 825-830. [CrossRef]

20. Valiev, R.Z.; Islamgaliev, R.K.; Alexandrov, I.V. Bulk nanostructured materials from severe plastic deformation. Prog. Mater. Sci. 2000, 45, 103-189. [CrossRef]

21. Estrin, Y.; Vinogradov, A. Extreme grain refinement by severe plastic deformation: A wealth of challenging science. Acta Mater. 2013, 61, 782-817. [CrossRef]

22. Mozaffari, A.; Danesh Manesh, H.; Janghorban, K. Evaluation of mechanical properties and structure of multilayered Al/Ni composites produced by accumulative roll bonding (ARB) process. J. Alloys Compd. 2010, 489, 103-109. [CrossRef]

23. Saito, Y.; Utsunomiya, H.; Tsuji, N.; Sakai, T. Novel Ultra-High Straining Process for Bulk Materials Development of the Accumulative Roll-Bonding (ARB) Process. Acta Mater. 1999, 47, 579-583. [CrossRef]

24. Zhou, W.; Lin, J.; Dean, T.A.; Wang, L. Feasibility studies of a novel extrusion process for curved profiles: Experimentation and modelling. Int. J. Mach. Tools Manuf. 2018, 126, 27-43. [CrossRef]

25. Zhou, W.; Lin, J.; Dean, T.A. Manufacturing a curved profile with fine grains and high strength by differential velocity sideways extrusion. Int. J. Mach. Tools Manuf. 2019, 140, 77-88. [CrossRef]

26. Yu, J.; Lin, J.; Dean, T.A. Development of novel differential velocity sideway extrusion tichniques to fabricate lightweight curved structural component. Procedia Manuf. 2020, 50, 125-128. [CrossRef]

27. Liddicoat, P.V.; Liao, X.-Z.; Zhao, Y.; Zhu, Y.; Murashkin, M.Y.; Lavernia, E.J.; Valiev, R.Z.; Ringer, S.P. Nanostructural hierarchy increases the strength of aluminium alloys. Nat. Commun. 2010, 1. [CrossRef] [PubMed]

28. Cardoso, K.R.; Travessa, D.N.; Botta, W.J.; Jorge, A.M., Jr. High Strength AA7050 Al alloy processed by ECAP: Microstructure and mechanical properties. Mater. Sci. Eng. A 2011, 528, 5804-5811. [CrossRef]

29. Elhefnawey, M.; Shuai, G.L.; Li, Z.; Nemat-All, M.; Zhang, D.T.; Li, L. On achieving superior strength for Al-Mg-Zn alloy adopting cold ECAP. Vacuum 2020, 174, 109191. [CrossRef] 
30. Brodova, I.G.; Shirinkina, I.G.; Rasposienko, D.Y.; Akopyan, T.K. Structural Evolution in the Quenched Al-Zn-Mg-Fe-Ni Alloy during Severe Plastic Deformation and Annealing. Phys. Met. Metallogr. 2020, 121, 899-905. [CrossRef]

31. Shirinkina, I.I.G.; Brodova, I.G. Annealing-induced structural-phase transformations in an Al-Zn-Mg-Fe-Ni alloy after high pressure torsion. Phys. Met. Metallogr. 2020, 121, 344-351. [CrossRef]

32. Brodova, I.G.; Petrova, A.N.; Akopyan, T.K. The influence of severe plastic deformation on the structure and mechanical properties of eutectic Al-Zn-Mg-Fe-Ni alloy. IOP Conf. Ser. Mater. Sci. Eng. 2019, 672, 012022. [CrossRef]

33. Akopyan, T.K.; Belov, N.A.; Aleshchenko, A.S.; Galkin, S.P.; Gamin, Y.V.; Gorshenkov, M.V.; Cheverikin, V.V.; Shurkin, P.K. Formation of the gradient microstructure of a new Al alloy based on the Al-Zn-Mg-Fe-Ni system processed by radial-shear rolling. Mater. Sci. Eng. A 2019, 746, 134-144. [CrossRef]

34. Lomakin, I.V.; Arutyunyan, A.R.; Valiev, R.R.; Gadzhiev, F.A.; Murashkin, M.Y. Design and evaluation of an experimental technique for mechanical and fatigue testing of sub-sized samples. Exp. Tech. 2017, 42, 261-270. [CrossRef]

35. Zhang, Y.D.; Jin, S.B.; Trimby, P.; Liao, X.Z.; Murashkin, M.Y.; Valiev, R.; Sha, G. Strengthening mechanisms in an ultrafine-grained $\mathrm{Al}-\mathrm{Zn}-\mathrm{Mg}-\mathrm{Cu}$ alloy processed by high pressure torsion at different temperatures. Mater. Sci. Eng. A 2019, 752, 223-232. [CrossRef]

36. Sauvage, X.; Murashkin, M.Y.; Straumal, B.B.; Bobruk, E.V.; Valiev, R.Z. Ultrafine grained structures resulting from SPD-induced phase transformation in Al-Zn alloys. Adv. Eng. Mater. 2015, 17, 1821-1827. [CrossRef]

37. Nurislamova, G.; Sauvage, X.; Murashkin, M.; Islamgaliev, R.; Valiev, R. Nanostructure and related mechanical properties of an Al-Mg-Si alloy processed by severe plastic deformation. Philos. Mag. Lett. 2008, 88, 459-466. [CrossRef]

38. Razumov, I.K. Nonequilibrian grain boundary segregation in alloys subjected to severe plastic deformation. Condens. Matter Interphases 2010, 12, 394-399.

39. Valiev, R.Z.; Enikeev, N.A.; Murashkin, M.Y.; Kazykhanov, V.U.; Sauvage, X. One origin of the extremely high strength of ultrafine-grained $\mathrm{Al}$ alloys produced by severe plastic deformation. Scr. Mater. 2010, 63, 949-952. [CrossRef]

40. Zou, Y.; Wu, X.; Tang, S.; Zhu, Q.; Song, H.; Cao, L. Co-precipitation of T' and $\eta^{\prime}$ phase in Al-Zn-Mg-Cu alloys. Mater. Charact. 2020, 169, 110610. [CrossRef]

41. Sauvage, X.; Enikeev, N.A.; Valiev, R.Z.; Nazedkina, Y.; Murashkin, M.Y. Atomic-scale analysis of o the segregation and precipitations mechanism in a severely deformed Al-Mg alloys. Acta Mater. 2014, 72, 125-136. [CrossRef]

42. Kazantzis, A.V.; Chen, Z.G.; De Hosson, J.T.M. Deformation mechanism of aluminum-magnesium alloys at elevated temperatures. J. Mater. Sci. 2013, 48, 7399-7408. [CrossRef] 